\title{
First extraction of eDNA from tree hole water to detect tree frogs: a simple field method piloted in Madagascar
}

\author{
Katherine E. Mullin ${ }^{1}$ D $\cdot$ Izabela M. Barata ${ }^{2}$ D $\cdot$ Jeff Dawson $^{2}$ D $\cdot$ Pablo Orozco-terWengel $^{1}$ (D)
}

Received: 3 June 2021 / Accepted: 10 November 2021 / Published online: 26 November 2021

(c) The Author(s) 2021

\begin{abstract}
Environmental DNA (eDNA) is becoming an increasingly used tool for monitoring cryptic species within terrestrial and aquatic systems. We present the first method for extracting water from tree holes for eDNA studies of tree-dwelling frogs, and the first use of eDNA for amphibian monitoring in Madagascar. This pilot study expands on a previously developed method and aims to provide a simple field protocol for DNA extraction from very small water samples, using a relatively inexpensive kit compared to other collection methods. We collected $20 \mathrm{ml}$ of water from tree holes in Ambohitantely Special Reserve in Madagascar, with the aim to survey for the Critically Endangered tree frog Anodonthyla vallani, and we developed species specific cytochrome c oxidase 1 primers for this species. While our two samples did not detect A. vallani, we successfully extracted up to $16.6 \mathrm{ng} / \mu \mathrm{l}$ of eDNA from the samples and using 16S rRNA primers barcoded the tree frog Plethodontohyla mihanika in one of the samples. Despite just two samples being collected, we highlight the future potential of eDNA from tree holes for investigating cryptic habitat specialist amphibians given we extracted frog eDNA from just $20 \mathrm{ml}$ of water. The method provides a rapid, simple, and cost-effective method which can assist cryptic species monitoring in challenging and time-consuming field conditions and should be developed further for frog surveying in Madagascar and beyond. The newly developed primers can be used for further work using this eDNA method to survey threatened Anodonthyla frog species.
\end{abstract}

Keywords Environmental DNA $\cdot$ Amphibian $\cdot$ Herpetology $\cdot$ Rare species $\cdot$ Survey methods $\cdot$ Monitoring

\section{Introduction}

The use of environmental DNA (eDNA) in conservation biology is becoming an increasingly popular non-destructive method for wild species surveying (Thomsen and Willerslev 2015). It has been used on a range of species including fish, amphibians, coral reefs and mammals, and in a range of environments including the ocean, fresh water streams and rivers, ponds, bromeliads and soil (Huerlimann et al. 2020). This method detects DNA which has been shed by a species who may or may not still be present within the environment.

Katherine E. Mullin

mullink@cardiff.ac.uk

Pablo Orozco-terWengel

Orozco-terWengelPA@ cardiff.ac.uk

1 Cardiff University, School of Biosciences, Sir Martin Evans Building, Museum Avenue, Cardiff CF10 3AX, UK

2 Durrell Wildlife Conservation Trust, Les Augrès Manor, Trinity JE3 5BP, Channel Islands, Jersey
It has been used to detect whole communities (Lopes et al. 2017; Sasso et al. 2017), but also cryptic (Torresdal et al. 2017; Bálint et al. 2018), threatened (Thomsen et al. 2012) and invasive species (Dejean et al. 2012), even when a species may be present at low population densities (Sasso et al. 2017). eDNA is becoming an increasingly popular tool for amphibian surveying and there is growing evidence that detection rates may be as efficient as more traditional visual encounter and acoustic surveying (Lopes et al. 2017; Bálint et al. 2018; Barata et al. 2021).

eDNA metabarcoding of stream water has been used to successfully detect all known frog species present within a tropical ecosystem in Brazil (Lopes et al. 2017) and for three focal species this method had a greater capacity of detection per sampling than traditional rapid visual and audio field surveys. Further research used eDNA to target 30 amphibian species of conservation concern in Brazil, and successfully detected species that had locally disappeared, and one species which has not been seen since 1968 (Lopes et al. 2020). These results support that eDNA could perform better for detecting cryptic species which are not recorded using 
traditional survey techniques, and it may be a more powerful approach for presence absence studies in comparison to acoustic sampling as it records all individuals of a species at any life stage rather than just calling adult males (Takahara et al. 2020).

Small terrestrial water sources such as inside bromeliads have been surveyed for frog eDNA, and three studies have successfully used the method to survey for endangered species (Brozio et al. 2017; Torresdal et al. 2017; Barata et al. 2021). Barata et al. (2021) compared eDNA results with visual encounter surveys and found eDNA to provide reliable estimates with very low error, and the estimated occupancies were very similar between the two methods. They concluded that this eDNA method is an alternative to destructive bromeliad searching when conducting presenceabsence studies. Meanwhile Torresdal et al. (2017) discovered a new population of a non-target species using eDNA in bromeliads, increasing its limited range from two to three sky islands. To date, eDNA has not been used to survey tree holes, an important source of water for many species' life history. While the conditions inside tree holes are different to those inside bromeliads (e.g., not directly exposed to UV radiation) they are similarly difficult to survey; especially to detect elusive and cryptic species, and they are equally challenging in terms of the feasibility of the eDNA method due to the small water sample available for extraction. Given that tree-holes and bromeliads pose similar challenging conditions for DNA extraction we expect the eDNA method to be equally feasible for such environments/microhabitats.

The New Sahonagasy Action Plan 2016-2020 for Madagascar's amphibians had aim 2.7 'Investigate and develop the use of environmental DNA for monitoring species' (Andreone et al. 2016). Currently the only eDNA sampling conducted in Madagascar was to detect the deadly amphibian fungus Batrachochytrium dendrobatidis and Ranavirus in stream water (Kolby et al. 2015). Tree frog species such as those in the families Hylidae, Microhylidae and Rhacophoridae, occupy tree holes and use them for their reproductive lifecycle and hence tree hole water eDNA could be a reliable surveying method for monitoring tree frogs around the world. To our knowledge eDNA has not been used in Madagascar for frog surveying and monitoring despite recommendations in the action plan, the island's vast and unique amphibian diversity, and the access difficulties for many locations.

The aim of this pilot study was to develop a potential survey method for elusive and cryptic frog species dependent on tree holes. The objectives were to (1) develop a method that can successfully extract water from a tree hole, (2) determine whether it is possible to detect amphibian eDNA from the small amounts of water present in tree holes and (3) develop species specific primers for the target species Anodonthyla vallani to assess the potential for eDNA as a survey method for this species. A. vallani is a Critically Endangered cryptic frog endemic to Ambohitantely Special Reserve, in the central plateau of Madagascar. It is thought that this little known species uses tree holes as breeding sites (IUCN 2020) and is often heard calling in the canopy at 2-3 m (Vences et al. 2010). As such, acoustic monitoring was suggested as the best method for monitoring this species in comparison with visual surveys (Barata et al. in press) but this method may only detect adult males. Given its habitat restrictions and species vulnerability to extinction a non-invasive eDNA method would be a valuable tool in facilitating future presence-absence studies and further enhance targeted conservation monitoring.

\section{Methods}

Many filtering methods were considered to ensure a toolkit which did not need electricity for the pump, and which was lightweight for carrying long distances in the field. We adapted the method Barata et al. (2021) used for bromeliad water sampling, using similar equipment and adding a clear polyethylene round tube to be put down the tree hole (Table 1). This kit can be procured inexpensively in comparison to others that contains, for example, a pump. All non-sterile/pre-packaged equipment was sterilised under ultraviolet light and following UV treatment all equipment was packaged in the laboratory into individual closed bags for each sampling location (Fig. 1).

\section{Sample collection}

Upon finding a tree hole in the field the surveyor put on a pair of sterile gloves. We assessed how much water was likely inside the tree hole, to ensure that not all water was removed. The clear plastic tubing was removed from the sterile kit and pushed over the end of the $60 \mathrm{ml}$ syringe Luer inlet and the other end was put into the tree hole. The $60 \mathrm{ml}$ syringe was aspirated to pull water up the tubing. As in Barata et al. (2021) we planned on collecting $120 \mathrm{ml}$ of water $(2 \times 60 \mathrm{ml}$ full syringe $)$, however the tree holes did not contain sufficient amounts of water, such that just $20 \mathrm{ml}$ was collected. As a reduced volume of water was used, the surveyor had to remove the tubing and use gravity to get the remaining water into the syringe. Effort was made to avoid sediment; however, this was not possible with such small volumes of water present in the tree hole. The tubing was detached, the $60 \mathrm{ml}$ syringe locked into the Sterivex filter and the water was pushed into the chamber and across the filter allowing excess water to flow out of the outlet. This water passes out of the outlet into the environment. Once all of the collected water had been passed through the filter, a Luer lock was placed on the 
Table 1 Tree hole eDNA equipment list included in one single-use kit

\begin{tabular}{|c|c|c|c|}
\hline & Item & Supplier & Note \\
\hline 1 & $\begin{array}{l}\text { Sterivex-GV } 0.22 \mu \mathrm{m} \text {, with Luer outlet (no } \\
\text { fitting bell) }\end{array}$ & Merck Millipore & Sterile packaged \\
\hline 2 & Pair of sterile gloves & & \\
\hline 3 & $\begin{array}{l}\text { Clear polyethylene round tubing ( } \sim 60 \mathrm{~cm} \text { per } \\
\text { sample) }\end{array}$ & & $\begin{array}{l}\text { Plastic tubing from a non-specialised hardware } \\
\text { store. UV sterilised before packed for the } \\
\text { field. Size should make a tight seal over the } \\
\text { Luer syringe }\end{array}$ \\
\hline 4 & $60 \mathrm{ml}$ plastic syringe & Fisherbrand 14955461 & $\begin{array}{l}\text { Sterile packaged } \\
\text { With Luer lock (locks onto Sterivex) }\end{array}$ \\
\hline 5 & Needle $\times 1$ & $\begin{array}{l}\text { BD Microlance } \\
40 \mathrm{~mm}\end{array}$ & $\begin{array}{l}\text { Sterile packaged } \\
\text { To inject the preservation buffer into the } \\
\text { Sterivex chamber }\end{array}$ \\
\hline 6 & $5 \mathrm{ml}$ plastic syringe (for the storage buffer) & Medicina Luer Slip IV syringe & Sterile packaged \\
\hline 7 & $4 \mathrm{ml}$ storage buffer (Longmire) & & $\begin{array}{l}\text { Stored in } 2 \mathrm{ml} \text { microcentrifuge tubes wrapped } \\
\text { in parafilm }\end{array}$ \\
\hline 8 & $1 \times 50 \mathrm{ml}$ Falcon tube & & $\begin{array}{l}\text { To put Sterivex filter in once water has been } \\
\text { filtered }\end{array}$ \\
\hline 9 & Parafilm $\times 2$ squares & & $\begin{array}{l}\text { To wrap about the Luer locks to ensure no } \\
\text { leakage or contamination }\end{array}$ \\
\hline 10 & Plastic zip-lock bag & & Containing sterile equipment \\
\hline 11 & Luer locks $\times 2$ & Universal UN940 Obturator Male/Female & $\begin{array}{l}\text { Sterile packaged with both male and female } \\
\text { ends }\end{array}$ \\
\hline 12 & Permanent marker pen & & One for each bag \\
\hline
\end{tabular}

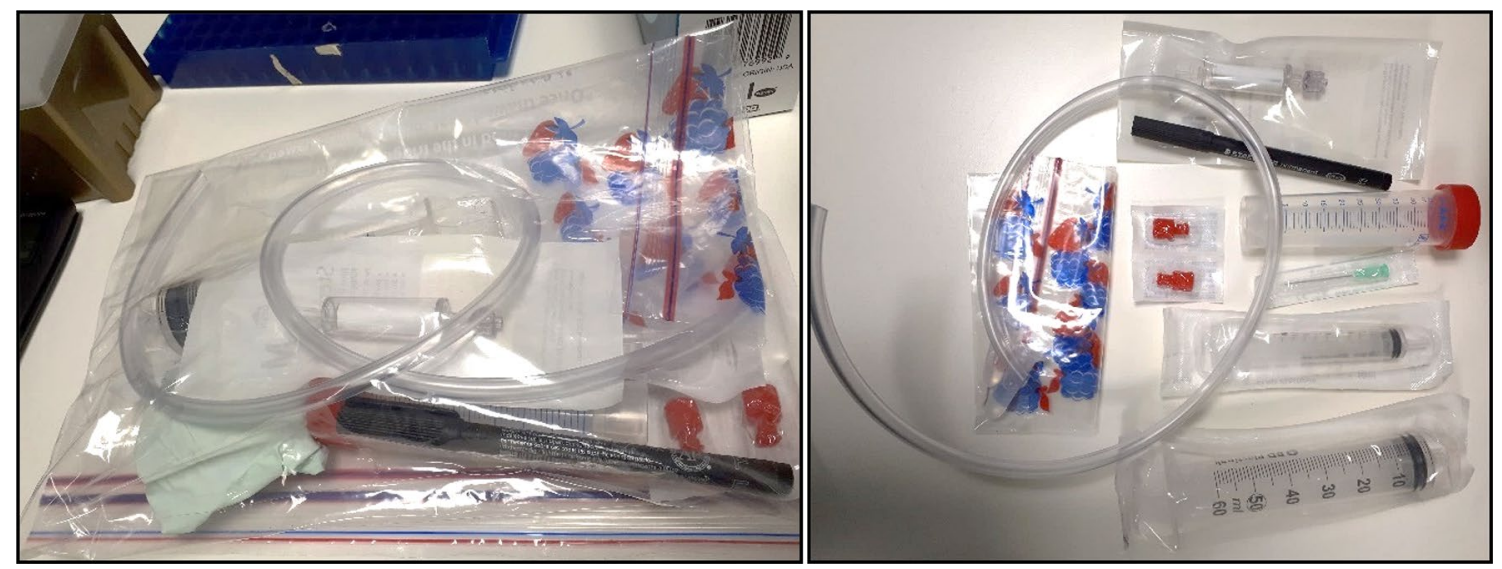

Fig. 1 Images to show the small size of one tree hole eDNA sampling kit. Right, clockwise; Sterivex filter, permanent marker pen, falcon tube, sterile needle, $5 \mathrm{ml}$ syringe, $60 \mathrm{ml}$ syringe, plastic tubing, luer locks and preservation buffer in $5 \mathrm{ml}$ tubes inside a small ziplock bag

filter outlet. A needle was attached to the $5 \mathrm{ml}$ syringe and the Longmire buffer was aspirated. The needle was placed inside the filter inlet and careful effort was made to not puncture the filter, but to pass the Longmire buffer into the filter chamber. The chamber was filled so that the filter was covered in preservation buffer. The inlet end was then locked with the Luer lock, and both ends were covered in parafilm to ensure no leakage or evaporation. The filter was placed in a labelled $50 \mathrm{ml}$ falcon tube for storage and sealed in the ziplock bag. Filters, tubes and ziplock bags were given the same individual number for lab identification. A falcon tube of local rainwater was kept in order to refill the holes; however, this was not necessary. We used homemade Longmire preservation buffer (Longmire et al. 1997) rather than ethanol given our remote field conditions, lack of immediate freezer storage, and air travel. For one litre of buffer, we used $100 \mathrm{ml} 1 \mathrm{M}$ Tris, $100 \mathrm{ml}$ 
$1 \mathrm{M}$ EDTA, $50 \mathrm{ml} \mathrm{10 \%} \mathrm{SDS,} 2 \mathrm{ml} 5 \mathrm{M} \mathrm{NaCl}, 20 \mathrm{ml}$ of $10 \%$ $\mathrm{NaN}_{3}$ and $728 \mathrm{ml} \mathrm{H}_{2} \mathrm{O}$.

We aimed to collect 15 samples; from true positives (i.e., A. vallani identified as present in the hole by visual surveys), from holes with unknown frog presence (i.e., hole visually surveyed but species either absent or undetected) and field blanks as true negatives (drinking water). However, this was not possible due to the COVID19 pandemic cutting fieldwork short, resulting in just two samples being collected from tree holes (Fig. 2) and one field blank from bottled water. Sample 1 was collected from a tree hole containing a few frog eggs of an unknown species. For this sample, $20 \mathrm{ml}$ of water were collected due to the shallow depth of the tree hole. Sample 2 was from a hole used by a male A. vallani in the previously surveyed year (2019) and had many unidentified tadpoles inside. Again just $20 \mathrm{ml}$ were collected due to the small size of the hole.

\section{Anodonthyla vallani primer development}

To advance the potential of this method as a survey technique for A. vallani, species specific primers were developed. The three available $A$. vallani cytochrome oxidase subunit 1 (COI) sequences from GenBank (KF611407.1, KM509758.1 and GU177059.1) were aligned with seven novel COI sequences (K Mullin, unpublished). All ten sequences were identical. The ten sequences were then aligned with COI barcodes of 33 anuran species local to Ambohitantely (K. Mullin, unpublished) in MEGAX (Kumar et al. 2018) using the ClustalW alignment algorithm. Non-target species used and their barcodes are available in Supplementary Information 1. Polymorphisms unique to A. vallani were identified visually and Geneious Prime 2021 (https://www.geneious. com) was used to design primers that aligned on those sites with the expectation that they would only amplify $A$. vallani DNA during PCR. The locations of the polymorphisms can be seen in bold in Table 2. The software was asked to create 'Precise' primers, between 18 and 27 bases in length, and with a Tm between 50 and 63 . GC \% was left at the default of optimal 50\%. Generating a relatively short PCR product (131 bp) is necessary for qPCR analysis and is suitable for the eDNA target given potential degraded DNA fragments.

The primers were tested in silico to ensure they were species specific using Primer-BLAST and the GenBank non-redundant (nr) amphibia taxon database. The BLAST search indicated that the primers may amplify A. vallani as well as two other Anodonthyla species (Anodonthyla theoi and Anodonthyla nigrigularis), both of which are not present in Ambohitantely. Primers were tested and annealing temperatures optimised using PCR temperature gradients

Table 2 Primers developed for Anodonthyla vallani

\begin{tabular}{lllll}
\hline Primer name & Length & $\mathrm{Tm}$ & GC\% & Sequence \\
\hline AVCOI-F & 24 & 58.7 & 37.5 & $\begin{array}{c}\text { TTAAACA- } \\
\text { GCAGC- } \\
\end{array}$ \\
& & & & CAAA \\
& & & CTTACAA \\
& & & C \\
AVCOI-R & 23 & 60.69 & 47.83 & TCTGGT \\
& & & & GCA \\
& & & & GCAATTA \\
& & & & TTAGGGG \\
& & & &
\end{tabular}

Bold highlights the polymorphisms between $A$. vallani and the other species local to Ambohitantely
Fig. 2 Tree holes sampled (left sample 1, right sample 2)
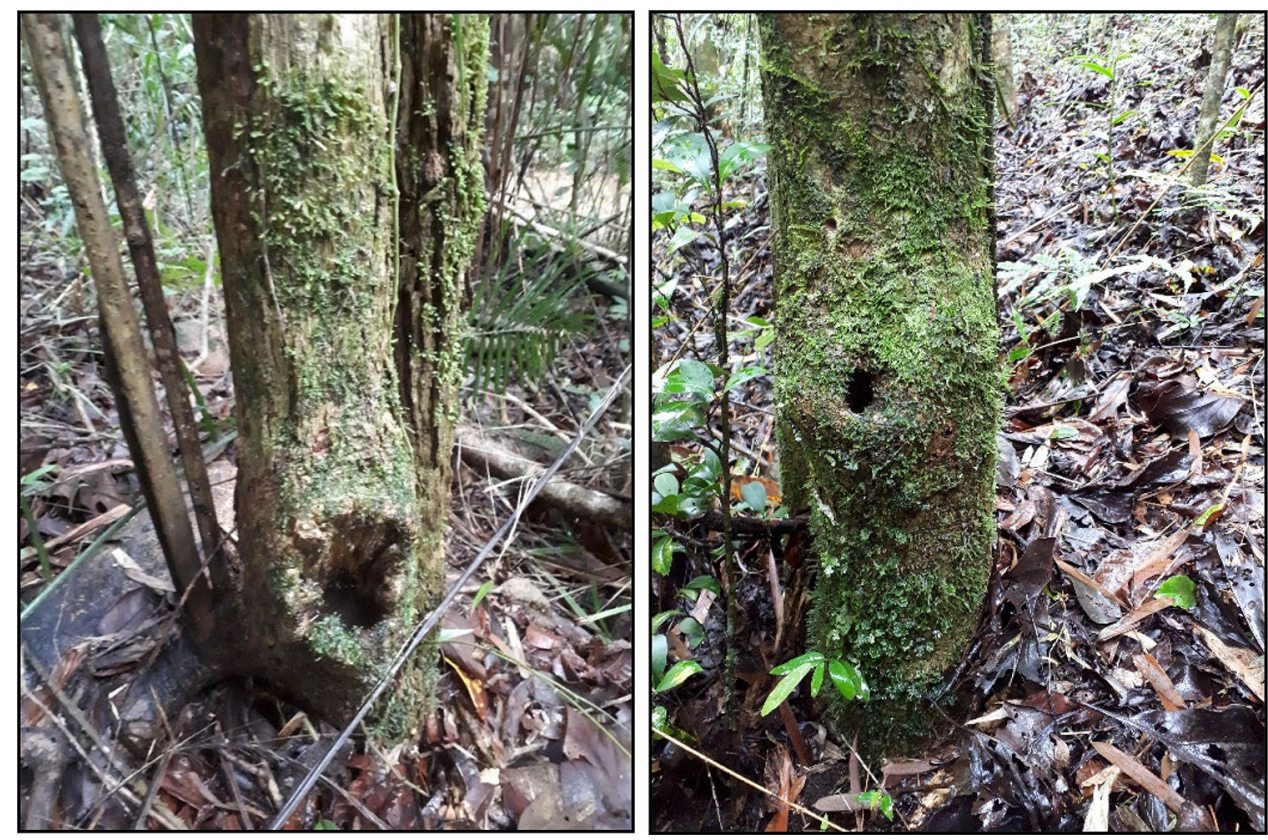
on nine confirmed $A$. vallani samples. Once optimisation was complete, they were tested for cross amplification on 24 other previously barcoded amphibian species recorded at Ambohitantely during our survey period (Supplementary Information 1), using DNA from buccal swab samples with concentrations similar to the A. vallani samples $(<1 \mathrm{ng} / \mu \mathrm{l})$. A negative control was included at the end of the strips to ensure there was no contamination in the PCR. A $12.5 \mu \mathrm{l}$ reaction volume was used using $1 \mu \mathrm{l}$ DNA, $1 \mu \mathrm{l} 5 \times$ Green GoTaq ${ }^{\circledR}$ Flexi reaction buffer (Promega), $1.5 \mu \mathrm{l} \mathrm{MgCl}_{2}$ $(25 \mathrm{mM}), 0.6 \mu \mathrm{l}$ deoxynucleotide (dNTPs $10 \mathrm{mM}), 0.3 \mu \mathrm{l}$ of each primer (10 pmol), $0.06 \mu \mathrm{l}$ of $5 \mu / \mu \mathrm{l} \mathrm{GoTaq}{ }^{\circledR}$ G2 Flexi DNA Polymerase (Promega), and molecular biology-grade $\mathrm{H}_{2} \mathrm{O}$. PCR thermo-cycling conditions were as follows: $5 \mathrm{~min}$ at $95{ }^{\circ} \mathrm{C}$, followed by 35 cycles of $94{ }^{\circ} \mathrm{C}$ for $1 \mathrm{~min}, 68^{\circ} \mathrm{C}$ for $1 \mathrm{~min}$ and $72^{\circ} \mathrm{C}$ for $1 \mathrm{~min}$, finishing with an elongation step of $72{ }^{\circ} \mathrm{C}$ for $10 \mathrm{~min}$. Our primers successfully amplified $A$. vallani DNA and none of the other 24 species.

\section{Lab method}

Given the simple aim of the study to develop a field sampling method to extract eDNA from limited amounts of tree hole water, combined with our small sample size, our lab method was simple and does not explore the current eDNA technology available. Instead, we tested our samples for $A$. vallani using the new primers, and also amplified a region of 16S rRNA to barcode any other species present within the samples.

\section{DNA extraction}

Filters were stored at room temperature for a maximum of 4 days and then were frozen for 1 year due to lab closures throughout the pandemic. They were fully defrosted to room temperature prior to extraction and the extraction method followed Spens et al. (2017) adaptation of the Qiagen DNeasy blood and tissue extraction kit protocol. Each filter had two extractions, one from the Longmire lysis buffer and one from the filter, plus one extraction control. The concentration of eDNA present in each sample (both filter and tube) was measured with the Qubit dsDNA High Sensitivity assay.

\section{A. vallani primer amplification}

Both samples were tested for $A$. vallani with the new primers following the PCR protocol developed above.

\section{S rRNA amplification}

The widely used mitochondrial 16S rRNA barcode was amplified to see if any frog DNA was present within the samples using the primer pair 16SA-L, 5'-CGC CTG TTT ATC AAA AAC AT-3' and 16SB-H, 5'-CCG GTC TGA ACT CAG ATC ACG T-3' (Palumbi et al. 1991). The same reaction volume and reagents were used as above. PCR thermo-cycling conditions were as follows: $3 \mathrm{~min}$ at $94{ }^{\circ} \mathrm{C}$, followed by 35 cycles of $94{ }^{\circ} \mathrm{C}$ for $30 \mathrm{~s}, 58^{\circ} \mathrm{C}$ for $30 \mathrm{~s}$ and $72{ }^{\circ} \mathrm{C}$ for $1 \mathrm{~min}$, finishing with an elongation step of $72{ }^{\circ} \mathrm{C}$ for $10 \mathrm{~min}$. A $12.5 \mu \mathrm{l}$ reaction volume was used, and PCR negatives were used to ensure no contamination.

\section{Results}

DNA was successfully extracted from both samples, from both the filter and lysis buffer (Table 3). Sample 2 had the highest DNA concentration with $16.6 \mathrm{ng} / \mu \mathrm{l}$ from the lysis buffer, but also the lowest concentration, $2.94 \mathrm{ng} / \mu \mathrm{l}$, from the filter. Sample 1 had more consistent concentrations of eDNA, with $11.0 \mathrm{ng} / \mu \mathrm{l}$ from the filter and again a higher concentration from the lysis buffer $(14.2 \mathrm{ng} / \mu \mathrm{l})$. The field blank was not contaminated, with no DNA registered on the Qubit, and no DNA amplified in either PCRs.

Anodonthyla vallani DNA was not amplified in either of the samples using the new primers. However, the 16S rRNA primers successfully amplified PCR products for Sample 2 (the hole with many tadpoles). This was sent to Eurofins Genomics for Sanger Sequencing and the obtained sequence was BLASTed through GenBank and identified as Plethodontohyla mihanika. The sequence obtained was a clean $16 \mathrm{~S}$ sequence trimmed to 553 base pairs and had a BLAST match of $97.55 \%$, E value 0.0 .
Table 3 Sample details; where the samples were collected, the amount of water collected, concentration of eDNA present within the sample, and the amplification success of $16 \mathrm{~S}$ rRNA, and the new A. vallani COI primers (AVCOI) $(\mathrm{Yes}=\mathrm{Y}$, $\mathrm{No}=\mathrm{N}$ )

\begin{tabular}{lllllll}
\hline Sample & GPS (Lat, Long) & Altitude $(\mathrm{m})$ & $\begin{array}{l}\mathrm{ml} \mathrm{H}_{2} 0 \\
\text { collected }\end{array}$ & $\begin{array}{l}\text { Total eDNA } \\
(\mathrm{ng} / \mu \mathrm{l})\end{array}$ & 16S & AVCOI \\
\hline 1 filter & $18.17536,047.30818$ & 1412 & 20 & 11.0 & $\mathrm{~N}$ & $\mathrm{~N}$ \\
1 tube & & & & 14.2 & & \\
2 filter & $18.14627,047.23699$ & 1463 & 20 & 2.94 & $\mathrm{Y}$ & $\mathrm{N}$ \\
2 tube & & $\mathrm{NA}$ & 60 & 0 & $\mathrm{~N}$ & $\mathrm{~N}$ \\
$\begin{array}{l}\text { Field blank filter } \\
\text { Field blank tube }\end{array}$ & $\mathrm{NA}$ & & & 0 & & \\
\hline
\end{tabular}




\section{Discussion}

While our sample size is small and our analysis method does not utilise the modern advancements in eDNA analysis, this study succeeds in its aim to provide a method to successfully extract frog eDNA from small volumes of water from tree holes. The method has the potential to be developed further for cryptic tree frog surveying in Madagascar and beyond, using quantitative PCR and metabarcoding technology (this was beyond the scope of this pilot study). We also show that just $20 \mathrm{ml}$ of water can hold enough detectable eDNA, which is a significantly reduced sample volume compared to most other freshwater studies when one or more litres of water are filtered (Williams et al. 2016; Bálint et al. 2018).

\section{Developing this for further use in Madagascar}

We were unable to detect $A$. vallani in our two samples using our simple laboratory method. This may be because A. vallani simply had not recently visited these two holes-throughout 444 survey hours just 13 A. vallani individuals were detected using VES, highlighting their low detection and abundance. Quantitative PCR (qPCR) could be developed to investigate these two samples in more detail, in case $A$. vallani DNA is present but in very low concentrations. The amplification of any frog DNA in Sample 1 was unsuccessful, compared to Sample 2. This could suggest that the eDNA of just a few eggs was not enough to amplify in a standard PCR, however a qPCR may be able to determine this, and further understand the threshold concentration at which DNA is successfully amplified.

A. vallani's distributional range is still unknown, having previously thought to exist in just two fragments (Vallan 2000), but since has been found in several more (K Mullin, unpublished). Given the inexpensive nature of this toolkit eDNA could be used to rapidly survey many fragments within Ambohitantely to further investigate A. vallani's range. All the equipment for a study to collect 50 samples would cost approximately $£ 500$, with one Sterivex filter costing $£ 7.60$ (2020). This advance cost would even out as less time is required in the field, reducing other field costs. This piloted method should be applied more widely and in much greater sample numbers to determine whether this method could indeed be used to monitor the species more efficiently, complimenting acoustic surveys which are thought to perform better than VES (Barata et al. in press). Based on previous datasets, the eDNA method could be trialled alongside VES and acoustic surveys to test its accuracy and efficiency for target species (as in
Takahara et al. 2020 and Barata et al. 2021), together with a cost-effective analysis to compare feasibility of different methods. Beyond Ambohitantely, we recommend trialling this method on the other two Endangered Anodonthyla species using the primers developed, and other tree frogs using metabarcoding.

Although we failed in detecting $A$. vallani from our two samples, we confirm the presence of $P$. mihanika-a species that was previously registered in the study area during visual surveys (KM, pers. obs.). This species is found at 500-1500 m asl, occupying pristine and degraded forests across central eastern Madagascar and due to its wide distribution is listed as Least Concern, however its population trend is unknown (IUCN 2016). The species is known to use water filled tree holes and bamboo stems for reproduction and is thought to exhibit parental care (Vences et al. 2003). A large survey effort is needed to record this species using visual encounter surveys (VES). Out of 1159 frogs surveyed across three sites during visual encounter surveys in March-May 2019 and January-March 2020, just 13 P. mihanika individuals were recorded (KM, unpublished data). Positive detection through eDNA from tree holes supports the use of this method to improve detection of cryptic species, widespread or range restricted, in Madagascar. The BLAST match of the eDNA sample was $97.55 \%$, which is similar to those of the two buccal swab samples we obtained during VES surveys (97.16\% and 98.78\%). Taxonomic exploration is still ongoing in Madagascar, and these results may suggest the species of Plethodontohyla in Ambohitantely are an unconfirmed candidate species with no reference sequences.

eDNA surveys can prevent misidentification of species and could identify cryptic species that are missed during VES surveys. For example, during VES surveys in Ambohitantely 35 frogs were found in tree holes, some of which could not be determined to species level based on the brief sighting before the frog dove down into the water. These are key examples of when eDNA would have been appropriate and when it could have given us more insight into A. vallani's distribution. Further, when just tadpoles are present only extremely experienced herpetologists may be able to identify to species level (and specimens would likely be necessary), and so eDNA can provide a non-invasive identification technique when no adult is present. In addition to the holes in which frogs were seen, there were countless other tree holes which could have been surveyed for eDNA when no frog was present. Given the low detection capacity of several species in Ambohitantely eDNA could help complete a community inventory, capturing those that go undetected through VES. Meta-barcoding could be developed to assist a community study. Like many other locations in Madagascar, surveying the fragments across Ambohitantely is challenging, with limited vehicular access, and a remote undulating 
landscape, requiring long hours of hiking to get to many of the forest fragments. Further, security concerns create unsafe night working conditions. These limitations prevent communities from being effectively surveyed across the protected area, but the use of eDNA could allow rapid surveys to be conducted across the landscape in daylight hours generating a more complete inventory.

\section{Limitations to tree hole eDNA collection}

When taking water from tree holes surveyors must be careful when eggs and tadpoles are present as they can easily be sucked up the tubing. Additionally, surveyors must not remove all water present within the tree hole to ensure the environment is not altered heavily or removed. If most of the water from a tree hole is removed, we strongly recommend refilling the hole with local rainwater to allow continued use. Ethical consideration should be used in terms of disturbing individuals who may be laying eggs, or who may exhibit parental care and have an adult present at the time to avoid causing disturbance.

eDNA surveys must consider the time of year. Detection may vary across seasons if species use tree holes only, or significantly more, during the breeding season (Takahara et al. 2020). While A. vallani and their offspring may spend more time in tree holes during the breeding season, it is likely that they occupy tree holes throughout the year, however when the rains are less the volume of water inside the holes will be less. Hence it is important to plan eDNA studies while considering ecological characteristics of a species, including any aspects of seasonality. It is assumed that $A$. vallani breed during the wet season (November-February) and so future eDNA surveys are advised for this time.

When such small amounts of water are present within the tree hole it is difficult to avoid collecting sediment, and this may have been a limitation for Sample 1. A large concentration of eDNA in Sample 1, and no amphibian amplification, may be largely due to the sediment that was picked up in this sample. eDNA from the sediment may overpower or inhibit any small amounts of amphibian DNA present, inhibition was not explored in this study. Meanwhile the higher eDNA concentration present in Sample 2 is likely to be largely amphibian DNA due to the high number of tadpoles present in the water and less sediment collection.

Another limitation of eDNA surveying is in-country capacity to access the materials and conduct the downstream processes such as DNA extraction, PCR reactions, and sequencing. These costs can be high and require some laboratory infrastructure. The equipment present in this kit requires no electricity (e.g. no water pump) and all items other than the filters are parts of medical equipment and so should be accessible in most countries. The use of Longmire lysis buffer as a preservation method prevents the barriers many international field workers face when using ethanol (e.g. difficult to source, and illegal to fly with). Higher concentrations of DNA were present in the Longmire buffer compared to on the filter, supporting the use of a lysis buffer for storage when ethanol cannot be used.

\section{Conclusion}

The use of eDNA in Madagascar has huge potential to further our understanding of the amphibian communities in Ambohitantely and elsewhere. Despite Madagascar's megadiverse amphibian fauna, over 500 species (Perl et al. 2014), many species and sites are still un-surveyed meaning there are significantly incomplete inventories of the island's fauna. For 130 species of amphibian in Madagascar, there are only one or two reliable records, while many others have fewer than ten records (Vieites et al. 2008). Baseline presence/absence knowledge is important for enabling conservation measures and developing monitoring efforts. In addition to tree hole sampling, eDNA metabarcoding of streams and forest swamps could enable rapid surveying and inventorying of whole communities across Madagascar. Our findings on the use of the eDNA method directly contributes to action 2.7 of the New Sahonagasy Action Plan, which lists Ambohitantely as a potential site for implementation of pilot eDNA studies. Further eDNA developments and applications could improve the understanding and knowledge of amphibians in Madagascar, their environment and threats, as specified in Theme 2 of the New Sahonagasy Action Plan. Environmental DNA presents an exciting opportunity to rapidly survey Madagascar's herpetofauna and to fill the inventory knowledge gaps.

Supplementary Information The online version contains supplementary material available at https://doi.org/10.1007/s12686-021-01245-0.

Acknowledgements We thank Cardiff University for ethical approval and the Madagascar Ministry of the Environment and Sustainable Development (MEDD) for providing our research permit $\mathrm{N}^{\circ} 332 / 19 /$ MEDD/SG/DGEF/DGRNE. We thank the Department of Animal Biology, University of Antananarivo for supporting the permits and larger project. We could have not conducted fieldwork without field guide Tovo Raditra from Madagascar National Parks, and research assistants Manoa G. Rakotomanga and Minosoa L. C. Razafiarimanana. We thank Durrell Wildlife Conservation Trust for providing financial and logistical support in the field. The UK Natural Environment Research Council supported this work through the GW4+ Doctoral Training Partnership NE/L002434/1.

Author contributions KM and IB developed the methodology. KM conducted the field and lab work. KM wrote the manuscript. IB, JD and POTW provided supervision throughout. All authors contributed to the manuscript.

Funding The UK Natural Environment Research Council supported this work through the GW4+ Doctoral Training Partnership NE/ 
L002434/1. The Durrell Wildlife Conservation Trust also funded this research.

Data availability Not applicable.

Code availability Not applicable.

\section{Declarations}

Conflict of interest The authors have no conflicts of interest to declare that are relevant to the content of this article.

Ethics approval Ethical approval from Cardiff University ethics panel and research permits approved by the Madagascar Ministry of the Environment and Sustainable Development (MEDD) N $332 / 19 / \mathrm{MEDD} / \mathrm{SG} /$ DGEF/DGRNE

Consent to participate Not applicable.

Consent for publication Not applicable.

Open Access This article is licensed under a Creative Commons Attribution 4.0 International License, which permits use, sharing, adaptation, distribution and reproduction in any medium or format, as long as you give appropriate credit to the original author(s) and the source, provide a link to the Creative Commons licence, and indicate if changes were made. The images or other third party material in this article are included in the article's Creative Commons licence, unless indicated otherwise in a credit line to the material. If material is not included in the article's Creative Commons licence and your intended use is not permitted by statutory regulation or exceeds the permitted use, you will need to obtain permission directly from the copyright holder. To view a copy of this licence, visit http://creativecommons.org/licenses/by/4.0/.

\section{References}

Andreone F, Dawson JS, Rabemananjara FCE, Rabibisoa NHC, Rakotonanahary TF (eds) (2016) New Sahonagasy Action Plan 20162020 / Nouveau Plan d'Action Sahonagasy 2016-2020. Museo Regionale di Scienze Naturali and Amphibian Survival Alliance, Turin

Bálint M, Nowak C, Marton O, Pauls SU, Wittwer C, Aramayo JL, Schulze A, Chambert T, Cocchiararo B, Jansen M (2018) Accuracy, limitations and cost efficiency of eDNA-based community survey in tropical frogs. Mol Ecol Resour 18:1415-1426. https:// doi.org/10.1111/1755-0998.12934

Barata I, Griffiths RA, Fogell DJ, Buxton AS (2021) Comparison of eDNA and visual surveys for rare and cryptic bromeliad-dwelling frogs. Herpetol J 31:1-9. https://doi.org/10.33256/hj31.1.19

Barata IM, Razafindraibe JH, Ravelojaona RN, Ralovarisoa E, Mullin K, Hudson MA, Dawson J (in press) First population estimates of two critically endangered frogs from an isolated forest plateau in Madagascar. Oryx

Brozio S, Manson C, Gourevitch E, Burns TJ, Greener MS, Downie JR, Hoskisson P (2017) Development and application of an eDNA method to detect the critically endangered Trinidad golden tree frog (Phytotriades auratus) in bromeliad phytotelmata. PLoS ONE 12:1-8. https://doi.org/10.1371/journal.pone.0170619

Dejean T, Valentini A, Miquel C, Taberlet P, Bellemain E, Miaud C (2012) Improved detection of an alien invasive species through environmental DNA barcoding: the example of the American bullfrog Lithobates catesbeianus. J Appl Ecol 49:953-959. https:// doi.org/10.1111/j.1365-2664.2012.02171.x

Huerlimann R, Cooper MK, Edmunds RC, Villacorta-Rath C, Le Port A, Robson HLA, Strugnell JM, Burrows D, Jerry DR (2020) Enhancing tropical conservation and ecology research with aquatic environmental DNA methods: an introduction for nonenvironmental DNA specialists. Anim Conserv 23:632-645. https://doi.org/10.1111/acv.12583

IUCN SSC Amphibian Specialist Group (2016) Plethodontohyla mihanika. The IUCN Red List of Threatened Species 2016: e.T57974A84181433. https://doi.org/10.2305/IUCN.UK.20161.RLTS.T57974A84181433.en

IUCN SSC Amphibian Specialist Group (2020) Anodonthyla vallani (amended version of 2016 assessment). The IUCN Red List of Threatened Species 2020: e.T190944A176030045. https://doi. org/10.2305/IUCN.UK.2020-3.RLTS.T190944A176030045.en

Kolby JE, Smith KM, Ramirez SD, Rabemananjara F, Pessier AP, Brunner JL, Goldberg CS, Berger L, Skerratt LF (2015) Rapid response to evaluate the presence of amphibian chytrid fungus (Batrachochytrium dendrobatidis) and ranavirus in wild amphibian populations in Madagascar. PLoS ONE 10(6):1-21. https:// doi.org/10.1371/journal.pone.0125330

Kumar S, Stecher G, Li M, Knyaz C, Tamura K (2018) MEGA X: molecular evolutionary genetics analysis across computing platforms. Mol Biol Evol 35:1547-1549

Longmire JL, Maltbie M, Baker RJ (1997) Use of "Lysis Buffer" in DNA isolation and its implication for Museum collections. Occassional Papers Museum of Texas Tech University (163)

Lopes CM, Sasso T, Valentini A, Dejean T, Martins M, Zamudio KR, Haddad CFB (2017) eDNA metabarcoding: a promising method for anuran surveys in highly diverse tropical forests. Mol Ecol Resour 17(5):904-914. https://doi.org/10.1111/1755-0998.12643

Lopes CM, Baêta D, Valentini A, Lyra ML, Sabbag AF, Gasparini JL, Dejean T, Haddad CFB, Zamudio KR (2020) Lost and found: frogs in a biodiversity hotspot rediscovered with environmental DNA. Mol Ecol 00:1-10. https://doi.org/10.1111/mec.15594

Palumbi S, Martin A, Romano S, McMillan WO, Stice L, Grabowski G (1991) The simple fool's guide to PCR. Ver. 2, p. 46. Honolulu: University of Hawaii.

Perl RGB, Nagy ZT, Sonet G, Glaw F, Wollenberg KC, Vences M (2014) DNA barcoding Madagascar's amphibian fauna. Amphibia Reptilia 35:197-206. https://doi.org/10.1163/15685381-00002942

Sasso T, Lopes CM, Valentini A, Dejean T, Zamudio KR, Haddad CFB, Martins M (2017) Environmental DNA characterization of amphibian communities in the Brazilian Atlantic forest: potential application for conservation of a rich and threatened fauna. Biol Cons 215(321):225-232. https://doi.org/10.1016/j.biocon.2017. 09.015

Spens J, Evans AR, Halfmaerten D, Knudsen SW, Sengupta ME, Mak SST, Sigsgaard EE, Hellström M (2017) Comparison of capture and storage methods for aqueous macrobial eDNA using an optimized extraction protocol: advantage of enclosed filter. Methods Ecol Evol 8(5):635-645. https://doi.org/10.1111/2041-210X. 12683

Takahara T, Iwai N, Yasumiba K, Igawa T (2020) Comparison of the detection of 3 endangered frog species by eDNA and acoustic surveys across 3 seasons. Freshw Sci 39:18-27. https://doi.org/ $10.1086 / 707365$

Thomsen PF, Willerslev E (2015) Environmental DNA - an emerging tool in conservation for monitoring past and present biodiversity. Biol Cons 183:4-18. https://doi.org/10.1016/j.biocon.2014.11.019

Thomsen PF, Kielgast J, Iversen LL, Wiuf C, Rasmussen M, Gilbert MTP, Orlando L, Willerslev E (2012) Monitoring endangered freshwater biodiversity using environmental DNA. Mol Ecol 21(11):2565-2573. https://doi.org/10.1111/j.1365-294X.2011. 05418.x 
Torresdal JD, Farrell AD, Goldberg CS (2017) Environmental DNA detection of the golden tree frog (Phytotriades auratus) in bromeliads. PLoS ONE 12(1):1-8. https://doi.org/10.1371/journal. pone. 0168787

Vallan D (2000) Influence of forest fragmentation on amphibian diversity in the nature reserve of Ambohitantely, highland Madagascar. Biol Cons 96(1):31-43. https://doi.org/10.1016/S0006-3207(00) 00041-0

Vences M, Raxworthy CJ, Nussbaum RA, Glaw F (2003) New Microhylid Frog (Plethodontohyla) from Madagascar, with Semiarboreal Habits and Possible Parental Care. Soc Study Amphib 37(4):629-636

Vences M, Glaw F, KÖhler J, Wollenberg KC (2010) Molecular phylogeny, morphology and bioacoustics reveal five additional species of arboreal microhylid frogs of the genus Anodonthyla from Madagascar. Contrib Zool 79(1):1-32
Vieites DR, Nieto-Roman S, Vences M (2008) Towards understanding the spatial pattern of amphibian diversity in Madagascar. A Conservation Strategy for the Amphibians of Madagascar, pp 397-409

Williams KE, Huyvaert KP, Piaggio AJ (2016) No filters, no fridges: a method for preservation of water samples for eDNA analysis. BMC Res Notes Biomed Central 9(1):1-5. https://doi.org/10. 1186/s13104-016-2104-5

Publisher's Note Springer Nature remains neutral with regard to jurisdictional claims in published maps and institutional affiliations. 